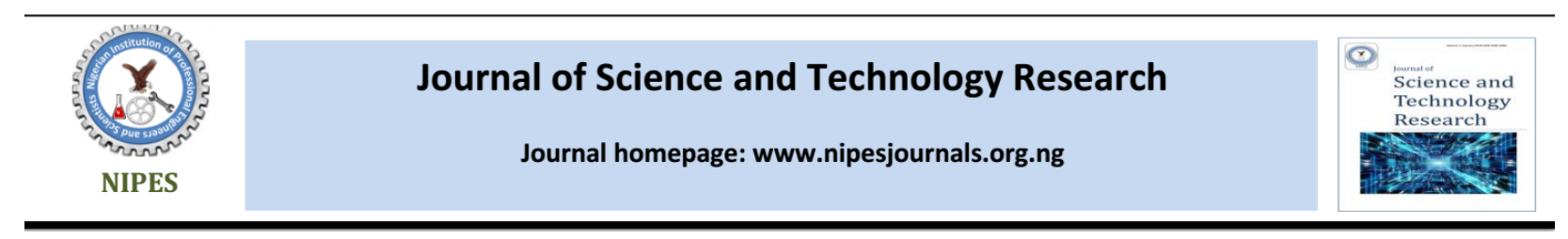

\title{
Contributing Impact of Climate Change on Sustainability of Bio-Degradable Material-Adaptation of Alternative Measures
}

\author{
Oludaisi Adekomaya* \\ Olabisi Onabanjo University, Department of Mechanical Engineering, Ogun State, Nigeria
}

\section{Article Info}

Keywords:

climate change, recycling,

biodegradable, materials

Article history:

Received 13 April 2020

Revised 24 April 2020

Accepted 02 May 2020

Available online 1 June 2020

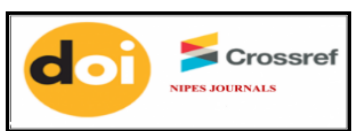

https://doi.org/10.37933/nipes/2.2.2020.9

https://nipesjournals.org.ng ISSN-2682-5821/@ 2020 NIPES Pub. All rights reserved.

\begin{abstract}
Containment of climate change requires a holistic approach from industrial players as experts face daunting challenges emanating from material use and reclamation. In view of effect of materials on environment, as revealed by non-recyclability of synthetic materials, this paper appraises existing climate change management options and proffer sustainable idea on mitigation of impact of climate change in most countries of the world. Water level are now rising with attendant loss in micro-structural base, couple with high temperature occasioned by depletion of ozone layer. Floods and droughts are among the existing barometers indicating the level of environmental resilience and carrying capacity. These parameters have been overstretched, a signal that may spell doom sooner than later. While the solution is still far from being over, this paper $x$-rays the worsening climate change despite the adaption of biodegradable materials in engineering applications. This paper discusses growing concerns on degradation of materials in engineering application thereby necessitating early replacement of materials as against their life span. Part of the approach discussed in this paper is the reinvigoration of recycling of used plastic materials as a sustainable reclamation option which tend to declines the global fossil fuel required in the manufacture of neat plastic and reduces the waste requiring disposal. This in a way, will save huge volume of fossil fuel required in the production of new plastic materials.
\end{abstract}

\section{Introduction}

The impact of climate change is being felt in all the corners of the world most importantly in the evolution of biodegradable materials [1]. The rate of rising ambient temperature is much faster now compared with what is experienced in the past 100 years [2]. This may not be unconnected with the fast depletion of the ozone layer occasioned by poor material selection in engineering application [3]. Part of the investigative report being advanced by environmentalists which have been affirmed elsewhere $[4,5]$ reveal that in the next 100 years, the average ambient temperatures will increase between $1.8^{\circ} \mathrm{C}$ and $4.0^{\circ} \mathrm{C}$. The implication of this high global temperature is better imagined than experienced [6]. This change portends high risk of strange weather conditions and infiltration of extreme natural disaster [7]. Plastic materials have been reported as a reliable solution to some of these challenges since they are inexpensive with weight saving properties and durability. These evolving properties of plastic has widened the application and the production of plastics over the 
last 80 years [8]. However, these volumetric productions of plastic materials have snowballed into other challenges with several environmental problems. Key of the inherent composition of plastic materials is non-renewable resource, i.e. about $3-4 \%$ of fossil reserve is used as major feedstock for plastic and the production of plastic materials itself further require 3-4\% of global energy. This is a complicated scenario as more fossil fuel utilization is always associated with environmental complications [9].

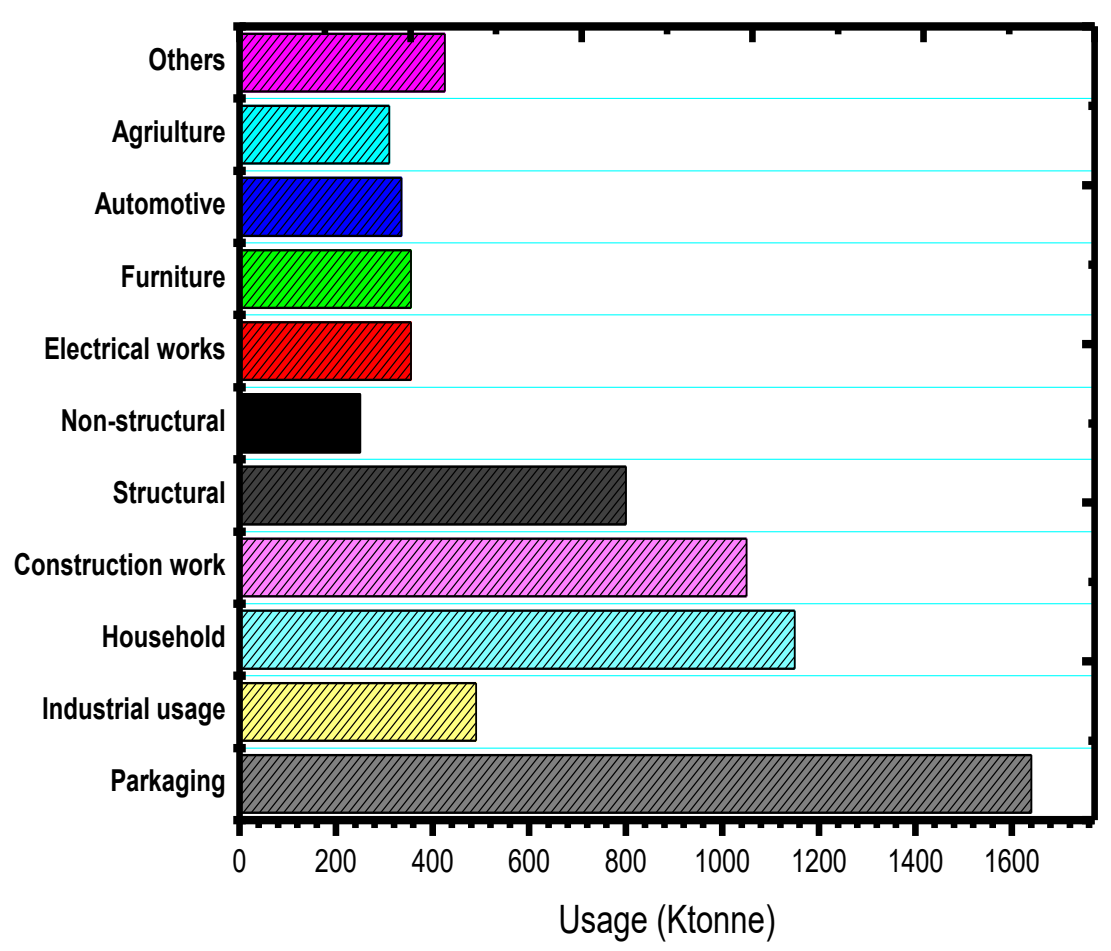

Figure 1: Application of biodegradable materials in engineering applications. Adapted from [10]

Figure 1 as shown is an illustrative example of biodegradable materials and their various application in ktonnes. It can be seen that packaging materials consume more plastic materials globally and their evolving waste is expected to be high in view of high material utilization. In another paper [11], findings have shown that large proportion of plastic materials generated each year is being applied to make disposable items and, in most cases, packaging is the first port of call. The most worrisome in some of these cases is that these products are short-lived and discarded within few months of production. This concern as shown in Figure 2 indicating waste arising from plastic application is an indication that the use of biodegradable materials may not after all combat climate change as predicted. Part of the concerns in another paper [12] has been the resilience of polymer materials in most biodegradable materials. This raises the quantities of discarded plastic materials which accumulate in form of debris as seen in most landfills and natural habitat globally. 


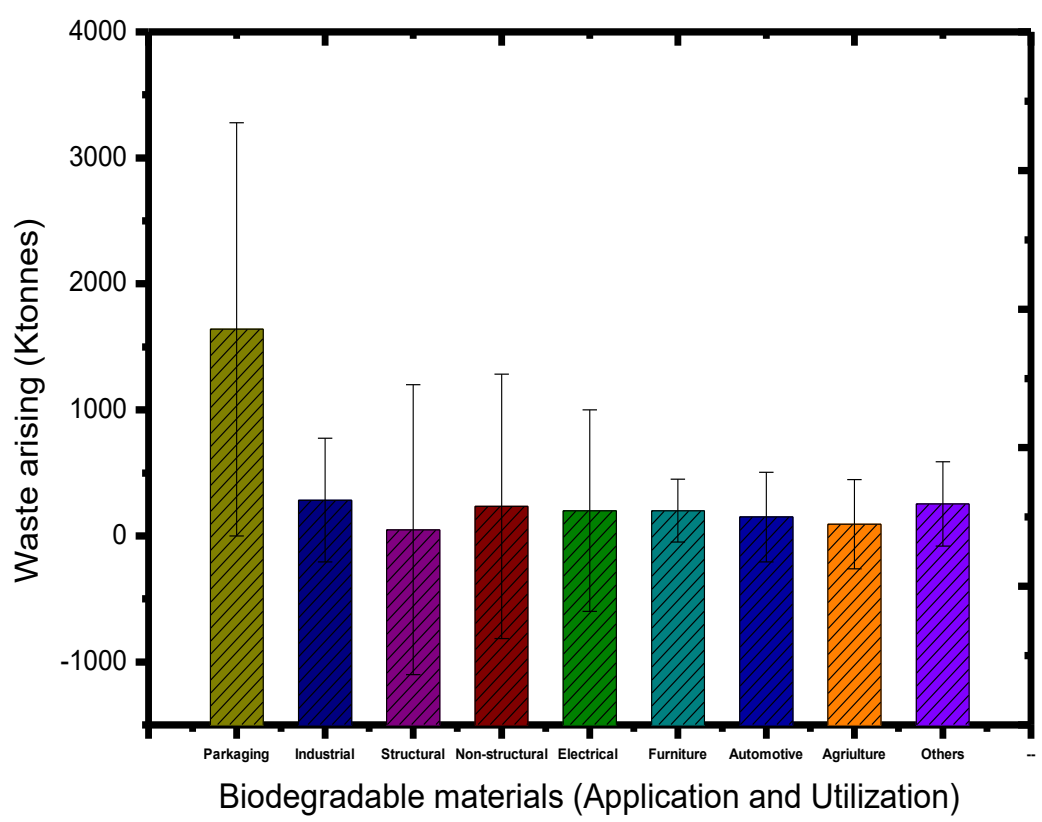

Figure 2: Waste arising from application of biodegradable materials. Adapted from [1, 2, 12]

While waste volume increases, there seem to be no harmonized intergovernmental linkages in the sustainable development goal (SDG) of the UN. Part of the key goal of SDG is geared toward a peaceful climate and efforts mounted by individual countries to mitigate climate change appear at cross level to one another. Global waste is predicted to rise as effort is being diverted to safe energy. The focal point will be the management of biodegradable materials since new technology explore this material to reduce weight and also of importance is their eco-friendliness. Automotive part formations are now 100\% biodegradable in most developed countries of the world [13]. The implication of this is that the end of life vehicles part will need to be monitored and managed so that these wastes do not constitute another burden to the environment. This concern is also being expressed in electrical and electronics equipment where plastic is now the source of components parts [14]. To broaden the sources of plastic waste, studies have shown that plastics have been excessively produced in the last 60 years, couple with the fact that their longevity in the environment cannot be ascertained as most literature [15]. Plastics are made with the primary intention of biodegradability and also to provide durability in adjoining applications. Studies have also revealed that majority of plastic produced today may remain on the environment depending on the prevailing climatic weather condition at a region of location. In other words, degradation rates is also a functions of landfills, terrestrial and marine environments as corroborated in the work [7]. With the degradation of plastic, it is still believed that small components of plastic debris persist and remain in landfill for several years [16].

\section{Alternative measure: The complication of plastics recycling}

The theory of plastic recycling is complex and better understood in literature than in real practice. Basically, recycling of plastic revolves round four stages as reported in past works [17]. These include primary, secondary, tertiary and quaternary which have been widely discussed in many published works. Part of the approach recently introduced in the recycling activities is seen in closed-loop method where in most cases the polymer components are separated from the sources of degradable constituents and thereafter applied. In another way, components feedstock is processed so that petrochemical products in these feedstocks are separated from the polymer for easy processing. Despite remarkable progress made in some of these approaches, it has been established 
that it is not as economical as reported. Rigamonti, et al. [12] were among the researchers who faulted the chemical recycling of polymers in view of setbacks recorded in the recycling of polyolefins. This led to total closure of testing plant as no reasonable progress was recorded [18]. The integration of biodegradable plastics to solve some of these challenges have also been reported to complicate waste management concepts $[19,20,21]$. The difficulty of sourcing biomass component of biodegradable materials has remained unresolved in many published works. This concept as mentioned in this paper is highly voluminous and clear analysis of experimental works are desired to establish further findings. Detailed clarifications on these concepts can be sourced in related published papers.

\section{Projections of biodegradable wastes}

Biodegradable materials are expected to come under intense pressure in the next two decades and the resulting implication may further worsen waste management strategy especially in developing countries of the world. In Europe and other surrounding countries, evolving biodegradable waste is still at nearly 3 percent per year, which is still in line with International Panel of Climate Change (IPCC) on sustainable development. Recycling of plastic waste in 2003 alone amounted to only 14.8 per cent of the waste plastic generated (from all sources) which was a huge success at that time. With increasingly waste sources and other complications expected from plastic waste re-cycling, it may likely be impossible to achieve a total recovery rate of 40 percent taking into consideration some of the underlying factors. This proportion of waste to be recycled is huge and could trigger environmental challenge. Figure 3 is a clear representation of waste arising from the application of materials. As shown, packaging materials may need to be alternated with other component of plastic materials since much waste is expected from this application. This may involve the experimentation of materials that are bio-based and the processing of such materials must be done in an eco-friendly manner. Further research works may also assist to ascertain which biodegradable materials stay longer on the environment beyond their stipulated decomposition period.

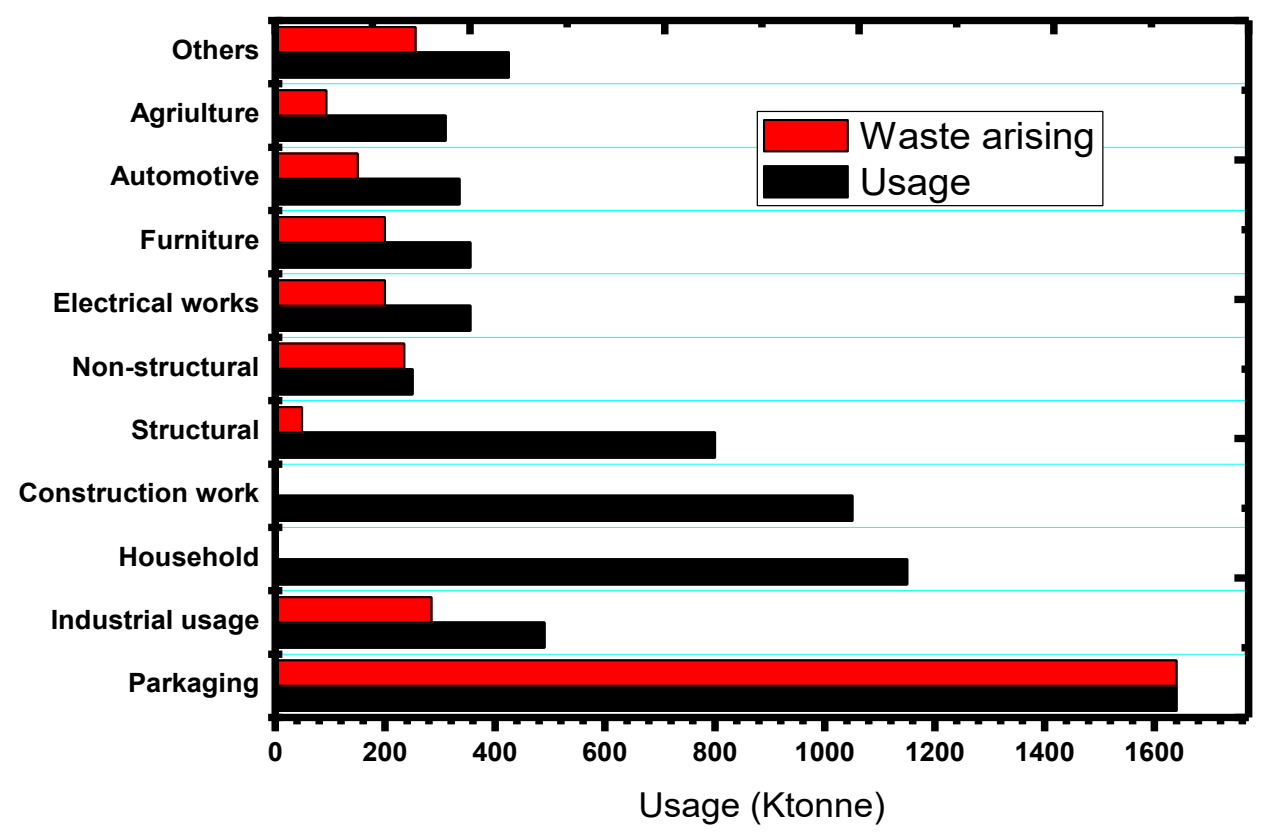

Figure 3: Prediction and projection of waste arising from the application of plastic materials Adapted from [10, 14. 19] 
In a way to reduce quantity of waste to be recycled, product design needs to be evaluated in all the emerging biodegradable material of today. This will further reduce various components of nonbiodegradable materials embedded in the plastic materials. A pilot test on a typical recycled shopping basket revealed lack of uniformity in the components structure as reported. Hence, broad assessment of existing waste recycling policies and implementation of source reduction of nonbiodegradable components in plastic materials is desired.

\section{Conclusion}

From all indications, recycling of plastic waste still remains a viable and sustainable solution for end-of-life waste management of plastic products. The impact of plastic waste generation on the environment is now very pronounced than before. The success recorded in some of these measures must be married with the source reduction approaches of plastic waste generation. This volume of waste derivable from plastic is expected to continue couple with the emergence of virgin plastic material. These two challenges must be critically researched in order to establish what needed to be done in finding a lasting solution to plastic waste which largely interface with the climate.

\section{Acknowledgment}

The author would like to appreciate Olabisi Onabanjo University, Nigeria for providing the platform to conduct this research. Appreciation also goes to various authors whose contributions were useful in the write-up.

\section{References}

[1] H. P. S. Abdul Khalil, M. S. Alwani, M. N. Islam, S. S. Suhaily, R. Dungani, Y. M. H'ng, et al., "16 - The use of bamboo fibres as reinforcements in composites," in Biofiber Reinforcements in Composite Materials, ed: Woodhead Publishing, 2015, pp. 488-524.

[2] O. Adekomaya, T. Jamiru, R. Sadiku, and Z. Huan, "Negative impact from the application of natural fibers," Journal of Cleaner Production, vol. 143, 2016, pp. 843-846.

[3] A. Felton, L. Gustafsson, J. M. Roberge, T. Ranius, J. Hjältén, J. Rudolphi, et al., "How climate change adaptation and mitigation strategies can threaten or enhance the biodiversity of production forests: Insights from Sweden," Biological Conservation, vol. 194, 2016, pp. 11-20.

[4] J. B. Smith, "Setting priorities for adapting to climate change," Global Environmental Change, vol. 7, 1997, pp. 251-264.

[5] S. Upgupta, J. Sharma, M. Jayaraman, V. Kumar, and N. H. Ravindranath, "Climate change impact and vulnerability assessment of forests in the Indian Western Himalayan region: A case study of Himachal Pradesh, India," Climate Risk Management, vol. 10, 2015, pp. 63-76.

[6] J. Lai, A. Harjati, L. McGinnis, C. Zhou, and T. Guldberg, "An economic and environmental framework for analyzing globally sourced auto parts packaging system," Journal of Cleaner Production, vol. 16, 2008, pp. 1632-1646.

[7] Z. Zhang, "Asian energy and environmental policy: Promoting growth while preserving the environment," Energy Policy, vol. 36,2008 pp. 3905-3924.

[8] N. Reddy and Y. Yang, "Biofibers from agricultural byproducts for industrial applications," Trends in Biotechnology, vol. 23, 2005, pp. 22-27.

[9] N. Abila, "Biofuels adoption in Nigeria: Attaining a balance in the food, fuel, feed and fibre objectives," Renewable and Sustainable Energy Reviews, vol. 35, 2014, pp. 347-355.

[10] J. Hopewell, R. Dvorak, and E. Kosior, "Plastics recycling: challenges and opportunities," Philosophical Transactions of the Royal Society B: Biological Sciences, vol. 364, pp. 2115-2126.

[11] R. Vasudevan, A. Ramalinga Chandra Sekar, B. Sundarakannan, and R. Velkennedy, "A technique to dispose waste plastics in an ecofriendly way - Application in construction of flexible pavements," Construction and Building Materials, vol. 28, 2012, pp. 311-320.

[12] L. Rigamonti, M. Grosso, J. Møller, V. Martinez Sanchez, S. Magnani, and T. H. Christensen, "Environmental evaluation of plastic waste management scenarios," Resources, Conservation and Recycling, vol. 85, 2014 , pp. 42-53. 


\section{Oludaisi Adekomaya / NIPES Journal of Science and Technology Research}

$$
\text { 2(2) } 2020 \text { pp. 102-107 }
$$

[13] O. O. Oguntoyinbo, "Informal waste management system in Nigeria and barriers to an inclusive modern waste management system: A review," Public Health, vol. 126, 2012, pp. 441-447.

[14] A. Luè, C. Bresciani, A. Colorni, F. Lia, V. Maras, Z. Radmilović, et al., "Future priorities for a climatefriendly transport. A European Strategic Research Agenda towards 2030," International Journal of Sustainable Transportation, 2016.

[15]P. Biswas and C.-Y. Wu, "Nanoparticles and the environment," Journal of the Air \& Waste Management Association, vol. 55, 2005, pp. 708-746.

[16]B. Phalan, A. Balmford, R. E. Green, and J. P. W. Scharlemann, "Minimising the harm to biodiversity of producing more food globally," Food Policy, vol. 36, Supplement 1, 2011, pp. 562-600.

[17] J. Gug, D. Cacciola, and M. J. Sobkowicz, "Processing and properties of a solid energy fuel from municipal solid waste (MSW) and recycled plastics," Waste Management, vol. 35, 2015, pp. 283-292.

[18] V. Kumar, L. Tyagi, and S. Sinha, "Wood flour-reinforced plastic composites: a review," Reviews in chemical engineering, vol. 27, 2011, pp. 253-264.

[19] O. Adekomaya, T. Jamiru, R. Sadiku, and Z. Huan, "Sustaining the shelf life of fresh food in cold chain - A burden on the environment," Alexandria Engineering Journal, vol. 55, 2016, pp. 1359-1365.

[20] O. Adekomaya, T. Jamiru, R. Sadiku, and Z. Huan, "Minimizing energy consumption in refrigerated vehicles through alternative external wall," Renewable and Sustainable Energy Reviews, vol. 67, 2017, pp. 89-93

[21] O. Adekomaya, T. Jamiru, R. Sadiku, Z. Huan, and M. Sulaiman, "Gas flaring and its impact on electricity generation in Nigeria," Journal of Natural Gas Science and Engineering, vol. 29, 2016 pp. 1-6, 